\title{
BUILDING THE HISTORY OF THE FUTURE: A TOOL FOR CULTURE- CENTRED DESIGN FOR THE SPECULATIVE FUTURE
}

\author{
F. Dong ${ }^{1, \otimes}$, S. Sterling ${ }^{1}$, D. Schaefer ${ }^{2}$ and H. Forbes ${ }^{2}$ \\ ${ }^{1}$ Xi'an Jiaotong-Liverpool University, China, ${ }^{2}$ University of Liverpool, United Kingdom \\ $\bigotimes$ Fangzhou.Dong@xjtlu.edu.cn
}

\begin{abstract}
In this paper, the authors propose a culture-centred tool called Speculative Ethnography to support the practice of design for the speculative future. Most explorations of tools and techniques of design for the speculative future focus on materialising the speculation. Instead, Speculative Ethnography provides a guideline to help designers define their speculation through the scientific imagination of the plausible future. It ensures the effectiveness of design for the speculative future and supports the interaction of culture and design for the speculative future.
\end{abstract}

Keywords: design tools, multi-/cross-/ trans-disciplinary approaches, social responsibility, speculative future, culture-centred design

\section{Introduction}

\subsection{Design for the speculative future}

Design is a future-oriented activity. Designers explore, express and test hypotheses about future ways of living (Sanders and Stappers, 2014). In Speculative Everything, Dunne and Raby (2013) illustrated the future with probable, plausible, possible and preferable cones (see Figure 1). It shows that the probable cone, where most of the normative designers operate, is not completely coincident with the preferable one. As the future is full of uncertainty, designers are encouraged to provide more possibilities especially in the plausible and possible cones, the alternatives to capitalism, to support collectively defining the preferable future.

There has been a group of emerging design genres that is distinct from the normative user-centred design which fits into the plausible and possible cones. Instead of focusing on solving problems and balancing stakeholder needs, they emphasize the social value of design by posing questions and arousing public discussions on potential social, political and ethical issues. There are multiple terms being used for the practice of these genres to describe similar but different approaches (e.g. see Auger, 2013; Kovačević et al., 2016; de Oliveira, 2016) such as critical and speculative design (Dunne and Raby, 2013), design fiction (Bleecker, 2009) and adversarial design (DiSalvo, 2015). For the purpose of this paper, design for the speculative future has been defined as design projects that aim at sparking public discussions on a preferable future through imagining and creating a plausible future. It is free from commercial constraints and it overlaps with the multiple terms mentioned above. 


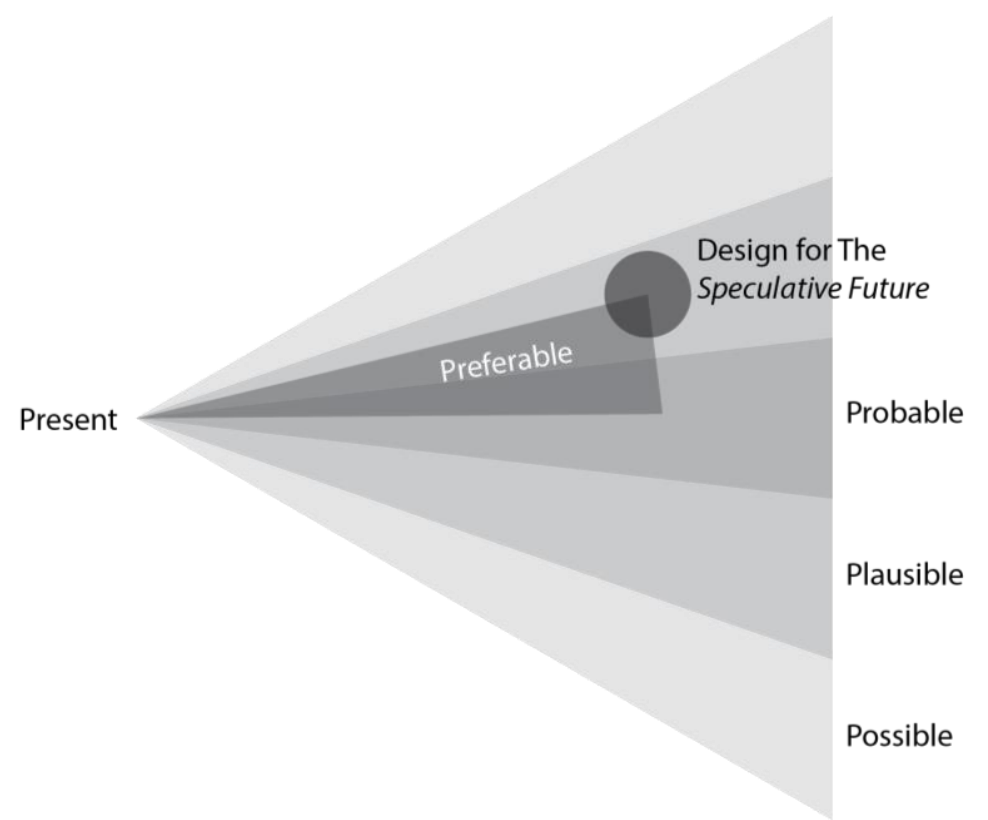

Figure 1. The future cones by Dunne and Raby $(2013$, p.5) and design for the speculative future

\subsection{Design, culture, and technology}

As Balsamo (2009) highlighted, culture is both a resource and an outcome of design practice. In normative design, user research is conducted to understand user needs so as to attract consumers. Participatory approaches, as other ways of understanding culture, involve stakeholders to participate in the designing process to balance and interpret their demands into products or services. The production of designed objects is the re-production of the material culture. People's behaviour as one component of culture has been changed when the design is consumed and utilised in daily life. Design for the speculative future is linked with culture without exception.

However, most of the existing interpretations of design for the speculative future are technologycentred, while the exploration of the intersection of culture and this design area is limited. Carl DiSalvo (2015) examines the ways that technology design can provoke and engage the political issues in Adversarial Design. Matt Ward states one of the roles of speculative design as "technological provocateur" (Kovačević et al., 2016, p.19). James Auger describes one purpose of it as "generating a better understanding of the potential implementations of a specific (disruptive) technology in various contexts and on multiple scales" (Kovačević et al., 2016, p.15). DiSalvo (2012) exams the ways of working of speculative design in the context of food culture and describes its process as "isolating facets of culture and recasting those facets in ways that alter their meaning" (p.111). The reshaped cultural facets are materialized and exhibited at galleries and museums as the networks for cultural exchange. On the other hand, although speculative design attempts to use design as a way of "comment upon culture" (p.110), its effects of communicating with audience through exhibitions are questioned, as it "failed to rouse to action" (p.119) (DiSalvo, 2012). Therefore, there is a need to explore new ways of supporting the interaction of culture and design for the speculative future.

\subsection{Focus of this paper}

This paper explores the intersection of culture and design and focuses on culture-centred design for the speculative future, using the practice of design for the future Chinese wedding as a case study. Culture is understood for the purpose of this paper as customs, behaviours and attitudes of the people related to the wedding. Utilizing the Research through Design approach (e.g. see Zimmerman et al., 2007), this paper proposes a new tool, called Speculative Ethnography, based on the design project experience of one of the authors as well as projects completed by student designers from the online speculative design studio at Canopy Institute of Design. This paper provides a guideline for 
Speculative Ethnography and is concluded by discussing how it supports the interaction between culture and design for the speculative future.

\section{Mapping speculative ethnography}

Speculative design has been seen more as an attitude or position than a methodology (Dunne and Raby, 2013), thus the practice of design for the speculative future is open for approaches, tools and techniques from all subjects that may be relevant to the specific design cases. Some scholars apply speculative design as a research method (e.g. Elsden et al., 2017; Sanders and Stappers, 2014). Nevertheless, there have been techniques and tools developed for this group of activities. Elsden et al. (2017) propose an experience-centred approach, Speculative Enactment, to enable the audience to interact with and experience the speculation. Auger (2013) and Dunne and Raby (2013) both propose some materialization techniques that bridge the speculative design concepts and the audience's perception such as "design for the context" (Auger, 2013, p.13), "desirable discomfort" (Auger, 2013, p.14), and "between reality and the impossible" (Dunne and Raby, 2013, p.139). Kirby (2009) borrows the ways of cinematic artefacts use to communicate the technology's implementation and proposes the concept of diegetic prototypes. Sometimes critical design and design fiction are seen as an approach themselves. Sterling (2013) describes design fiction as "the deliberate use of diegetic prototypes to suspend belief about change".

There is limited literature that includes reviews of the methods and tools used in the practice of design for the speculative future. Sanders and Stappers (2014) makes efforts to structure the approaches to making in co-design, which involves approaches to speculative future ("diegetic prototypes", "makebelieve role-playing with co-constructed artefacts" and "research through design prototypes", p.12). Kovačević et al. (2016) research into speculative design practice from the exhibition Design Fiction: Eutropia - Introduction to Speculative Design Practice and maps the tools and techniques in the British double diamond design process (see Figure 2). The tools are mapped mainly in the develop and deliver phases, which is consistent with the statement that a key element to the success of the speculative design is the communication with the audience (mainly through exhibitions) (see Auger, 2013; Dunne and Raby, 2013; DiSalvo, 2012).

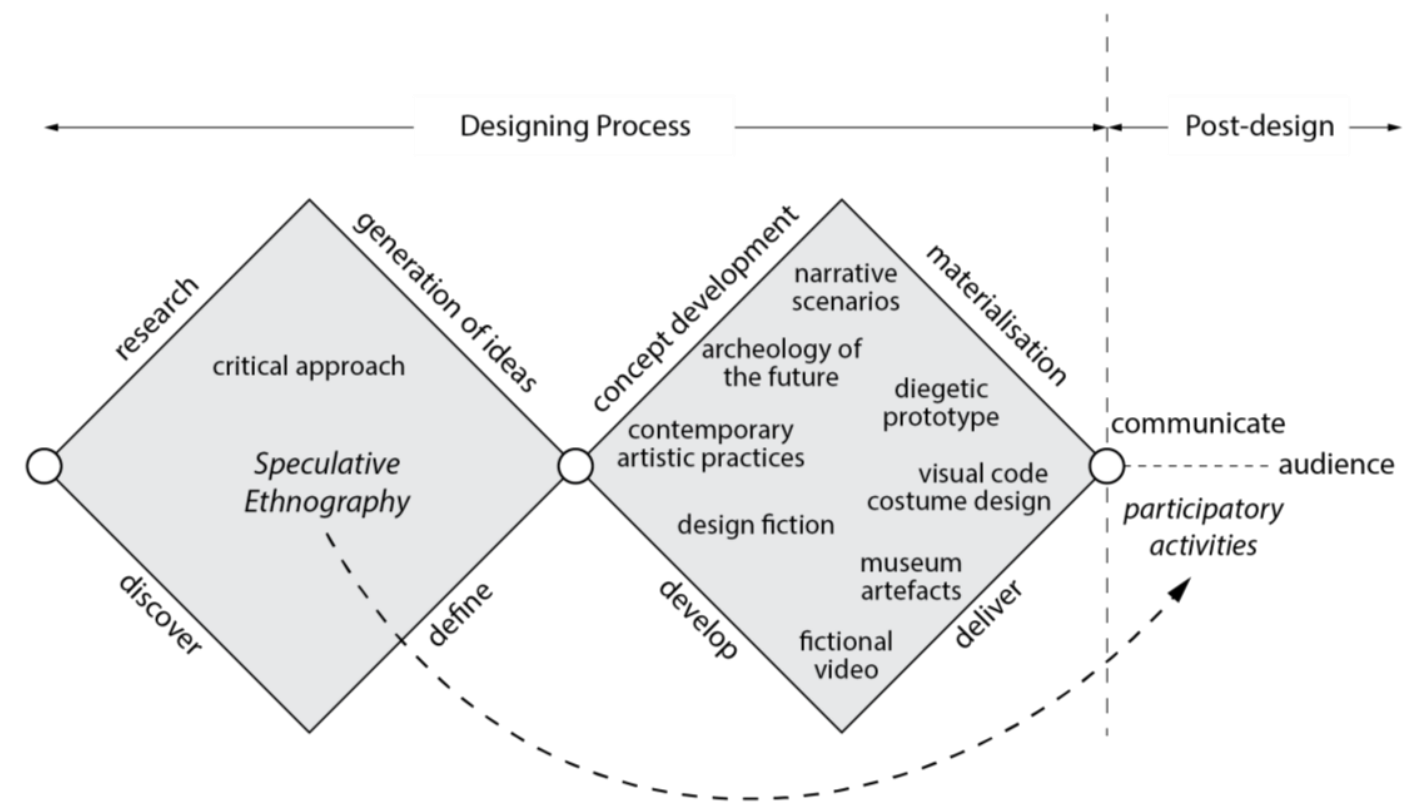

Figure 2. Tools and techniques mapped in the British double diamond approach

Speculative Ethnography is mapped in the discover and define phase in Figure 2 to support designers constructing the speculation. It contributes to propose a seemingly reasonable future culture following a logical thinking. It also contributes to the participatory activities in the post-design process, which are discussed later in this paper. 
As an anthropological methodology, ethnography describes culture through the immersive observation of people and society. It was introduced to the field of design at the Palo Alto Research Centre in the Industrial Design Human Interface at Xerox in the 1970s (Aiken, 2012). Subsequently, organisations increasingly adopt ethnographically-inspired techniques in design projects to deeply understand user behaviour (Kensing and Blomberg, 1998). Design ethnography is described as a discipline that identifies user needs by understanding how users live instead of asking what they want (Salvador et al., 1999). It relies on the present and helps understand "here and now" to inform the near future. Lindley et al. (2014) break its temporal constraints and formulate anticipatory ethnography, a theoretical space to open up dialogues about the distant future. Speculative Ethnography is considered as a practice in the field of anticipatory ethnography which adopts ethnographic research and informs and inspires design for the speculative future.

\section{Speculative ethnography in practice}

\subsection{Chinese wedding: general context}

The cases presented in this paper are designed under the context of Chinese wedding culture. Throughout history, the marriage ritual in China has been considered to be one of the most significant events for a family. The emperor of the Zhou Dynasty spent more than one year on his wedding; Prince of Tang Dynasty, Li Hong, also took approximately a year to marry his wife (Liu, n.d.). Despite China's long history and geographic diversities, the traditional marriage custom is divided into three sections: pre-wedding, wedding and after-wedding ceremonies (e.g. see Liu, 2019). This originates from the six etiquettes formulated by Duke of Zhou. The six etiquettes involve proposing, birthdates, bride price, dowry, arranging the wedding and the wedding ceremony (e.g. see Liu, 2019; Xue, 2015). The wedding ceremony is the most significant stage of the etiquettes, consisting of many elaborate rituals and wedding banquets. The clothing and accessories of the couple and other factors related to the ceremony such as the food on banquet are symbols of their wealth and status. The sequence and name of the six etiquettes vary across time periods and geographical locations. However, they follow the same core values, which is the Confucian tradition of patriarchal thought. The wedding is considered a celebration of carrying on the (male) ancestral line (Qu, 2000).

Since the Qing Dynasty, the marriage ritual has been gradually simplified. Nevertheless, the impact of the six etiquettes has not disappeared. Even today, the two families still prepare a bride price and dowry, and the wedding banquets remains as an essential section. In the modern context, Chinese brides and grooms are exposed to international fashion trends and wedding customs, which provide a greater variety of aesthetic choices to personalize their weddings. They have the choice as to hold a Chinese ceremony or a western church wedding, or both. There are then diversities among weddingrelated products in the past and present. For example, in the Chinese tradition, the bride and groom will wear in red on their wedding day to fit into the joyful atmosphere, as red is historically representative of good fortune and auspiciousness. In recent years the majority of newly married couples choose to wear in black and white (Zhang, 2012), which is more associated with elegance in a western context. Meanwhile, the function and value of the rituals have been transformed into a reallife celebration and social activity (Qu, 2000), which emphasizes the significance of the banquets. The dress-up and style of the banquets are the construction of the tastes and self-image of the new couple.

\subsection{Speculative ethnography projects}

\subsubsection{Virtual reality $(V R)$ wedding}

This project was conducted by one of the authors in 2019. It starts with the experience of attending several weddings without the groom and bride in Jining, Shandong province in China. The only elements indicating it as a "wedding" are candies, cigarettes and alcohol, typical items that appear in every wedding in China. Through interviews with young people from Jining and their parents, as well as people who have attended wedding ceremonies of this kind, it is common for young couples to have three or four or even more wedding banquets. They usually hold one banquet and ritual predominantly with the groom's family and friends of his parents, one banquet predominantly with the bride's, and one with the couple's 
colleagues and friends. Their parents may also hold some other banquets without the couple's attendance. Through design ethnography, in recent years, wedding trip is getting popular among the young. Many couples choose either a long travel to several destinations or a short trip to one destination. They then have a wedding ceremony before they come back and hold the banquets. Nevertheless, not all the friends of the couple are able to attend their wedding, as they may live and work in several cities.

Historically, there are two banquets at a Chinese wedding, one in the groom's family and another in the bride's some days later (called hui men yan in Chinese). The banquet in the groom's family, usually with a ritual before it, is the main one. Before globalisation when people seldom travelled, the groom and bride were often from the same town. In most of the cases, the two banquets were able to include almost all their relatives and friends. In a modern context, however, the development of transportation enables more long-distance travels, resulting in the couples' hometowns and working place to be three different cities, provinces or even countries. The number of wedding banquets thus rises to three or more, and the number of wedding ceremony remains one. One important reason for the increase is the geographical constraints has been broken gradually with the development of transportation and people's economic affordance.

It is therefore imagined that in the future, the couple would hold as many wedding "banquets" as they want thanks to internet technology and VR which enable the guests to attend their wedding online. Future wedding ceremonies would be VR videos available for invited guests. This speculated future has the potential to produce new culture components in different aspects. The couple would record their wedding ritual in the groom's family banquet using a panoramic camera, and provide cardboard VR glasses in other offline wedding banquets for the guests to experience their ritual. There would also be companies providing service to help the couple produce a pre-wedding VR ritual movie. The couples could build their self-images in the movie. There would be a "wedding Hollywood" for pre-wedding VR movie production. VR glass would become a necessity in wedding banquets along with traditional wedding candies, cigarettes and alcohol. The couples would be allowed to print their wedding invitation on the cardboard VR glasses and mail them to their friends so that they can attend the wedding online.

\subsubsection{Projects from speculative design studio}

This section describes two projects selected from student individual projects in a 7-week online design studio. There are five student designers participating in the studio, from architecture and urban planning background and these are their first projects in design for the speculative future.

Project 1 considers what is known as the "marriage house issue", being interested in the culture that the groom's family need to buy a house for the couple as the bride price. A reason for this is gender equality according to interviews. The student then researches gender equality issue in Chinese history, finding out that the rights of female to be more and more equal with that of male. The future is speculated that men and women would become absolutely equal in the marriage such as voice and decision-making. As a consequence of limited rationality and fairness of humans, an artificial intelligence (AI) system is involved to achieve absolute equality.

Project 2 focuses on the display of pre-wedding photography in China. Before the wedding banquets, Chinese new couples always take several sets of photos with different dress styles in each set. Although the era of film cameras is over, newlyweds still print out their pre-wedding photos and display the best one on the wall at home. The digital technologies expanded the possibilities for the couple to display their photos such as moments in social media. The student designer thus speculates physical wedding photos would always exist in the future, with digital technology playing some role. Ubiquitous computing and the Internet of Things are thus noticed, researched and applied in future scenarios.

\section{A guideline for speculative ethnography}

The term "speculative" has a strong relation with the conjectural and imaginary. One of the definitions of "speculate" in the Oxford English Dictionary is "to talk a matter over conjecturally" ("speculate, v.", 2019). It has been utilised in many areas and subjects - philosophers speculate (critical and speculative philosophy, see Broad, 1924), novelists speculate (speculative fiction, see Thomas, 2001). Besides its conjectural nature, to speculate requires logical thinking as philosophy does. Brassett (2016) involves the term "pragmatic", to describe a speculative philosophy as it generates the new, transforms the old and 
maps possibilities. Auger (2013) views the imagination of flying cars for instance as "wild speculations" and points out the possibility to "craft the speculation ... based on logical interactions" (p. 12). To avoid "wild speculations" in the designing process and distinguish the "design for" instead of "art of" the speculative future, Speculative Ethnography provides a guideline of four stages, focusing on now, past, trend and speculated future (see Figure 3) step by step, to help designers scientifically imagine the future.

1. Exploring the now

Begin by selecting a culture component as the research interests or questions, such as the wedding banquet in the VR ceremony case. It can be inspired by any common or special case or even anecdote. Conduct research of the selected component using anthropological methodologies, such as questionnaires, interviews, and visual ethnography to get knowledge of the current situation.

2. Tracing the past

Explore the causes of the current situation. This is potentially the bridge of the now and the past since history development may be one of the causes. Research into the history and investigate how and why ancestors deal with the selected culture component.

3. Generating the trend

Integrate the researched now and past, summarise the developing process of this culture component and generate it into a cultural trend. It contains what changed and what did not change throughout history. Summarise the fundamental reason for the trend, for instance in the VR ceremony case, the number of wedding banquets has changed due to the geographic constraints have been broken.

4. Approaching the speculated future

Scientifically imagine the speculated future scenarios by speculating on the future possibilities of the culture component based on the trends. Apply appropriate technologies that have an impact on the reason (e.g. internet technology and VR have been applied in VR ceremony since they further break the geographic constraints). Develop and materialise the speculation using tools and techniques in the develop and deliver phases in Figure 2 and other tools that fit the project.

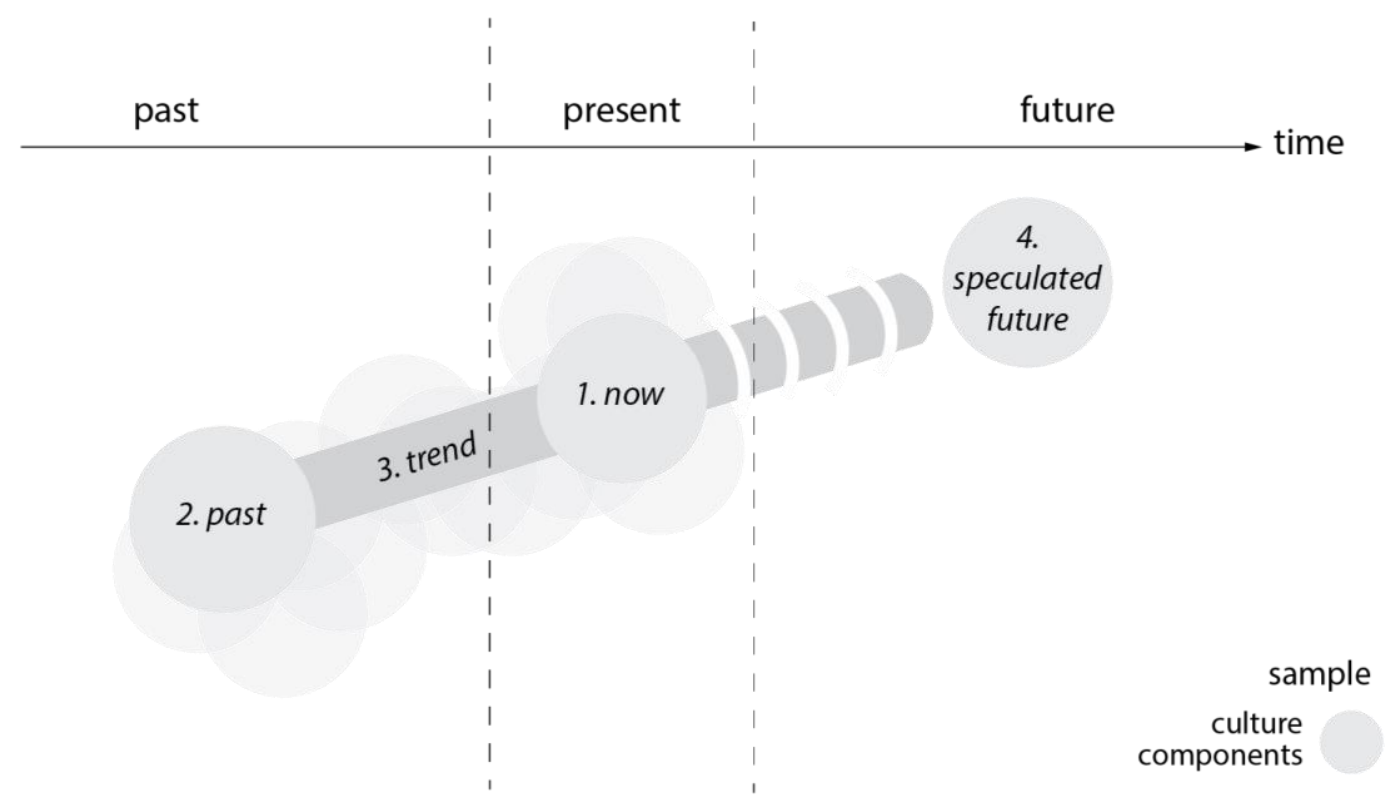

Figure 3. Structure of speculative ethnography

\section{Conclusion: Speculative ethnography and culture}

Speculative Ethnography is a culture-centred tool for design for the speculative future. It emphasises the concern for the cultural components in the entire designing process, rather than the development of technologies as most speculative practices focus on. It starts with the exploration of modern culture through design ethnography to learn people's behaviours and characteristics (i.e. the display behaviour 
of pre-wedding photography in student project 2), which is similar to the normative user-centred design. However, Speculative Ethnography researches the development of those behaviours and tends to stand in a more neutral position when describing them, instead of defining some cultural aspects as "problems". Culture is directly re-imagined through speculating the future behaviours during the construction of the speculated future. Contemporary technologies act as supporting elements in building future scenarios. It increases the possibility of the speculated future by materialising the re-imagined culture components. For instance, in student project 1 , the future culture is re-imagined as absolute equality, and the implementation of AI and the proposed AI system provides an example material culture of absolute equality. Speculative Ethnography is open-ended. The speculated future is the designers' way but not the only way to respond to the trend, which makes it possible to open up discussions and debates on the culture components that Speculative Ethnography stresses.

\section{Application scopes and next steps}

Although Speculative Ethnography is generated based on culture-centred projects, it could be utilised to a broader case. The provided guideline could be adjusted to be used more generally, providing it follows the structure of now, past, trend and future. One way it could be adapted is by considering the technological perspective. Auger (2013) separates the speculative design practice into two categories from the technological perspective: 1) speculative futures, which imagine the possible future developments of technology based on existing paradigms through materializing them on near future products and services; 2) alternative presents, which apply different ideologies or configurations of contemporary technology to current product development. Speculative Ethnography could be applied to scientifically imagine the future developments of technology in speculative futures. It could also be applied to speculate the possible ideologies or configurations of technology in alternative presents.

Opportunities also exist to utilise now, past, trend and future stages of Speculative Ethnography in another order in the participatory activities in the post-design process (see Figure 4), to enable deeper cultural exchange and rouse to action, which is the next research direction. The participatory post-design activities are alternatives to exhibitions that provide communication platforms for the audience and designers for the speculative future. The impact has been examined of participatory approaches on the interaction between culture and design for the speculative future in the former paper. Participants would be encouraged to reflect on the speculate future and imagine their preferred future scenarios. By integrating their preferred future and past, a speculated trend would be generated to describe the imagined developing process, and a speculated now would be approached. In other words, in order to approach the preferred future, the speculated now has to take place to support the speculated trend. With Speculative Ethnography, the productiveness and effectiveness of participation would be improved by enhancing the response to speculative concepts from the audience.

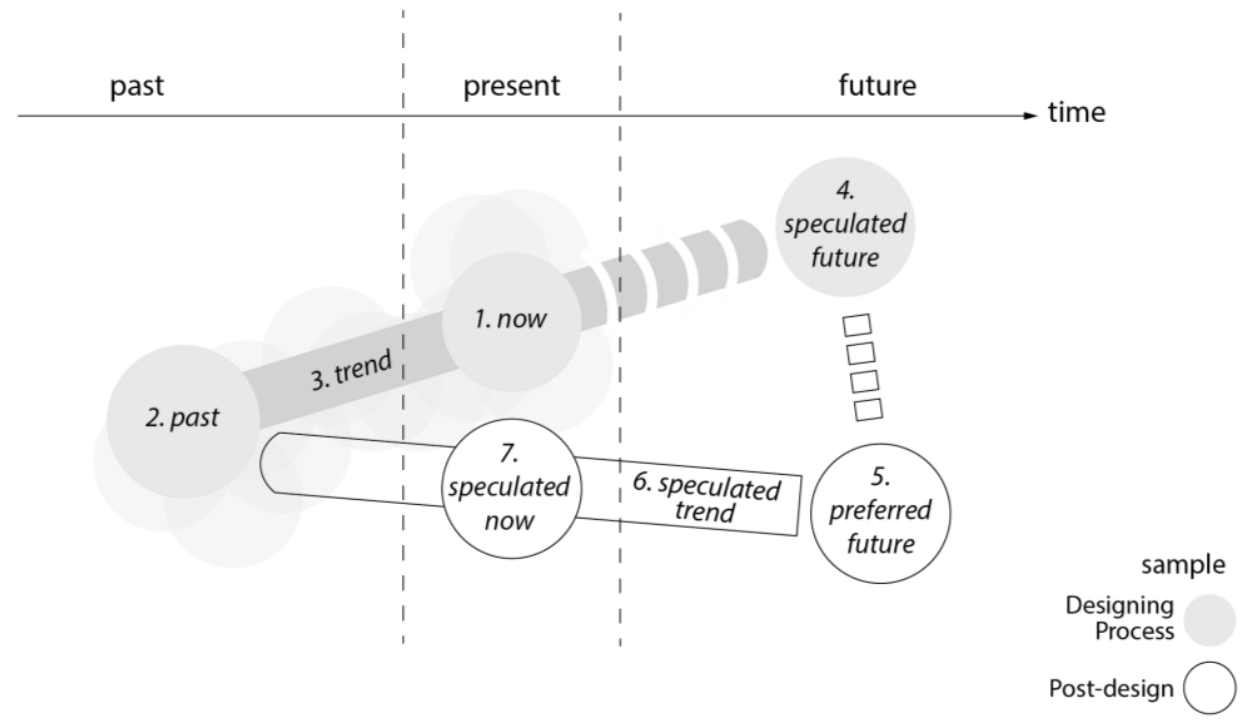

Figure 4. Structure of speculative ethnography and post-design activities 


\section{References}

Aiken, J. (2012), "Integrating Organizational and Design Perspectives to Address Challenges of Renewal: A case study of NASA's post-shuttle workforce transition", Proceedings of Ethnographic Praxis in Industry Conference, 2012, The American Anthropological Association, pp.163-176. https://doi.org/10.1111/j.15598918.2012.00018.x

Auger, J. (2013), "Speculative design: crafting the speculation”, Digital Creativity, Vol. 24 No. 1, pp.11-35. https://doi.org/10.1080/14626268.2013.767276

Balsamo, A. (2009), "Design”, International Journal of Learning and Media, Vol. 1 No. 4, pp. 1-10.

Bleecker, J. (2009), Design Fiction: A Short Essay on Design, Science, Fact and Fiction - Near Future Laboratory. [online] Near Future Laboratory. Available at: http://blog.nearfuturelaboratory.com/2009/0 3/17/design-fiction-a-short-essay-on-design-science-fact-and-fiction/ (Accessed 1 Nov. 2019).

Brassett, J. (2016), "Speculative machines and technical mentalities: a philosophical approach to designing the future", Digital Creativity, Vol. 27 No. 2, pp. 163-176. https://doi.org/10.1080/14626268.2015.1102745

Broad, C.D. (1924). Critical and speculative philosophy. Contemporary British Philosophy: Personal Statements, $77-100$.

Clarke, A. (2010), Design Anthropology: Object Culture in the 21 st Century, Bloomsbury.

de Oliveira, P. (2016), "Design at the Earview: Decolonizing Speculative Design through Sonic Fiction", Design Issues, Vol. 32 No. 2, pp. 43-52. https://doi.org/10.1162/DESI_a_00381

DiSalvo, C. (2012), "Speculative Design and Contemporary Food Cultures", The Fibreculture Journal, pp. 109-122.

DiSalvo, C. (2015), Adversarial design, MIT Press, Cambridge. https://doi.org/10.7551/mitpress/8732.001.0001

Dunne, A. and Raby, F. (2013), Speculative Everything: Design, Fiction, and Social Dreaming, MIT Press.

Elsden, C. et al. (2017), "On Speculative Enactments", Proceedings of the 2017 CHI Conference on Human Factors in Computing Systems - CHI '17. https://doi.org/10.1145/3025453.3025503

Kensing, F. and Blomberg, J. (1998), "Participatory Design: Issues and Concerns", Computer Supported Cooperative Work (CSCW), Vol. 7 No. 3-4, pp.167-185. https://doi.org/10.1023/a:1008689307411

Kirby, D. (2009), "The Future is Now: Diegetic Prototypes and the Role of Popular Films in Generating RealWorld Technological Development”, Social Studies of Science, Vol. 40 No. 1, pp. 41-70. https://doi.org/ $10.1177 / 0306312709338325$

Kovačević, L. et al. (2016), Speculative - Post-Design Practice or New Utopia, Ministry of Culture of the Republic of Croatia \& Croatian Designers Association.

Lindley, J., Sharma, D. and Potts, R. (2014), “Anticipatory Ethnography: Design Fiction as an Input to Design Ethnography”, Proceedings of Ethnographic Praxis in Industry Conference, 2014, pp.237-253. https://doi.org/10.1111/1559-8918.01030

Liu, X. (n.d.), Jiu tang shu [Old Book of Tang].

Liu. Y. (2019), "Jinan hunli gusu - yi Xingtai, Handan diqu weili [Wedding Customs in South Hebei Province: Case Studies of Xingtai and Handan area]", Journal of Xingtai University, Vol. 34 No. 2, pp. 33-38.

Qu, Y. (2000), "Zhongguo hunli yishi shilve [A Brief History of Chinese Wedding Rites]", Folklore Studies.

Salvador, T., Bell, G. and Anderson, K. (1999), "Design Ethnography", Design Management Journal (Former Series), Vol. 10 No. 4, pp. 35-41.

Sanders, E. and Stappers, P. (2014), "Probes, toolkits and prototypes: three approaches to making in codesigning”, CoDesign, Vol. 10 No. 1, pp.5-14. https://doi.org/10.1080/15710882.2014.888183

“speculate, v." (2019), In: Oxford English Dictionary, [online] Oxford University Press. Available at: https://www-oed-com.liverpool.idm.oclc.org/view/Entry/186112 (Accessed 2 Nov. 2019).

Sterling, B. (2013), Patently untrue: fleshy defibrillators and synchronised baseball are changing the future. [online] Wired.co.uk. Available at: https://www.wired.co.uk/article/patently-untrue (Accessed 1 Nov. 2019).

Thomas, S. (2001), Dark matter: A Century of Speculative Fiction from the African Diaspora, Grand Central Publishing.

Xue, F. (2015), Minguo shiqi Jiangnan hunsu fushi tanjiu [Wedding Dress in Period of the Republic of China to Explore the South of the Lower Reaches of the Yangtze River] [Master Thesis], Soochow University.

Zhang, Y. (2012), Zhongguo hunli fuzhuang de xianzhuang diaocha yu yingxiang hunsha liuxing [The Current Situation of Chinese Wedding Apparel and the Influence of Wedding Popularity], Liaoning Sichou.

Zimmerman, J., Forlizzi, J. and Evenson, S. (2007), "Research through design as a method for interaction design research in HCI", Proceedings of the SIGCHI Conference on Human Factors in Computing Systems - CHI '07. https://doi.org/10.1145/1240624.1240704 